\title{
A Correlation of Duration of Diabetes with Glycemic Indices in the Type 2 Diabetes Mellitus: A Prospective Study.
}

\author{
Anil Kumar Gupta ${ }^{1}$ \\ ${ }^{1}$ Assistant Professor, Department of General Medicine, MSY Medical College \& Hospital, Lalpur, Meerut, Uttar Pradesh, India.
}

\section{Abstract}

Background: The development of chronic complications is related to the duration of Diabetes Mellitus, however it may not reflect the true duration of disease, rather it reflects the time since diagnosis. The aim of this study to correlation of glycemic indices with duration of diabetes. Subjects and Methods: An observational study has done on 100 patients with type 2 diabetes mellitus in department of medicine, MSY Medical College \& Hospital, Lalpur, Meerut. Diabetes was diagnosed according to American Diabetes Association (ADA) revised criteria. Blood glucose level estimation was done by glucose oxidase method in venous blood. Glycosylated haemoglobin (HbA1C) was measured by ion-exchange chromatography method. Results: Our results showed that the 5-10 years of duration of diabetes was present in $42 \%$ cases and less than 5 years duration of diabetes was present in $40 \%$. HbA1c was not significant correlate but $>10$ years duration of diabetes was higher mean value as compared to less than 5 year duration of diabetes. Conclusion: We concluded that on applying spearman correlation for microvascular complications, a positive association was observed for age of patients, duration of diabetes, HbA1C. Duration of diabetes was found to be a main culprit of micro vascular complication.

Keywords: HbA1c, Diabetes Mellitus, Duration of Diabetes, Correlation.

Corresponding Author: Dr. Anil Kumar Gupta, Assistant Professor, Department of General Medicine, MSY Medical College \& Hospital, Lalpur, Meerut, Uttar Pradesh, India.

Received: June 2019

Accepted: June 2019

\section{Introduction}

Diabetes is a syndrome characterised by chronic hyperglycaemia and disturbance of carbohydrate, fat and protein metabolism associated with absolute or relative deficiencies in insulin secretion and/or insulin action. ${ }^{[1]}$

The prevalence of diabetes is rapidly rising all over the globe at an alarming rate. ${ }^{[2]}$ It is important to note that the rise in prevalence is seen in all six inhabited continents of the globe. ${ }^{[3]}$ Over the past 30 years, the status of diabetes has changed from being considered as a mild disorder of the elderly to one of the major causes of morbidity and mortality affecting the youth and middle aged people. Although there is an increase in the prevalence of type 1 diabetes also, the major driver of the epidemic is the more common form of diabetes, namely type 2 diabetes, which accounts for more than $90 \%$ of all diabetes cases. ${ }^{[4]}$

The development of chronic complications is related to the duration of Diabetes Mellitus, however it may not reflect the true duration of disease, rather it reflects the time since diagnosis. ${ }^{[5]}$ Longer the duration of diabetes, higher the frequency of diabetic nephropathy. Studies from different centres agreed that microalbuminuria is a strong predictor of subsequent development of overt diabetic nephropathy. ${ }^{[6]}$ Diabetic nephropathy is a clinical hall mark of microangiopathy. ${ }^{[7]}$ The most Common form of diabetic neuropathy is distal symmetric polyneuropathy involving sensory, motor and autonomic nerve fibres. ${ }^{[8,9]}$ Diabetic retinopathy is leading cause of blindness in developing country. ${ }^{[10]}$ It can be broadly categorized in to Non Proliferative and Proliferative Diabetic Retinopathy. ${ }^{[11]}$

There are few clinical studies in this direction but most of them lack sufficient power and are focused only towards one specific complication. The aim of this study to association of glycemic indices with duration of diabetes.

\section{Subjects and Methods}

An observational study done on 100 patients with type 2 diabetes mellitus in department of medicine MSY Medical College \& Hospital, Lalpur, Meerut.

\section{Inclusion Criteria}

- All diagnosed cases of T2DM defined by ADA as FPG $>126 \mathrm{mg} / \mathrm{dl}$ and $2 \mathrm{HPG}>200 \mathrm{mg} / \mathrm{dl}$

- Patients who taking specific medication for T2DM

\section{Exclusion Criteria}

- Patients with malignancy, liver disease, HBV, HCV and HIV

- Type 1 Diabetes Mellitus and Gestational Diabetes.

- Patient who had nephropathy before being diagnosed with Diabetes.

- Patients who do not provide consent. 


\section{Methods}

Each subject underwent detailed history and complete clinical examination. Details regarding age, sex, socioeconomic status, rural or urban, duration of diabetes and treatment history of diabetes were recorded for all the patients.

Diabetes was diagnosed according to American Diabetes Association (ADA) revised criteria. Blood glucose level estimation was done by glucose oxidase method in venous blood. Glycosylated haemoglobin (HbA1C) was measured by ion-exchange chromatography method.

\section{Statistical Analysis}

Significance of difference in proportion will be inferred by Chi-square test. Significance of difference in means will be inferred by unpaired ' $t$ '-test.

\section{Results}

Our results showed that the 5-10 years of duration of diabetes was present in $42 \%$ cases and less than 5 years duration of diabetes was present in $40 \%$. Only $18 \%$ cases had more than 10 years of diabetes [Table 1].

The mean value of $\mathrm{HbA1c}$ was higher $(9.765 \pm 2.139)$ in more than 10 years of duration of diabetes as compared to $5-10 \&<10$ years of duration of diabetes $(8.548 \pm 2.322$ and $8.490 \pm 2.488$ respectively). HbA1c was not significant correlate but $>10$ years duration of diabetes was higher mean value as compared to less than 5 year duration of diabetes [Table 2].

Table 1: Distribution of patients according to duration of diabetes

\begin{tabular}{|l|l|l|}
\hline Duration of diabetes & No. of patients & Percentage \\
\hline$<5$ yrs & 40 & $40 \%$ \\
\hline $5-10$ yrs & 42 & $42 \%$ \\
\hline$>10$ yrs & 18 & $18 \%$ \\
\hline Total & 100 & $100 \%$ \\
\hline
\end{tabular}

Table 2: Mean value of HbA1c according to duration of diabetes

\begin{tabular}{|l|c|c|c|c|c|c|}
\hline Glycemic control & \multicolumn{1}{|c|}{$\mathbf{5 y r s}$} & $\mathbf{5 - 1 0}$ yrs & $>10$ yrs & rs & 95\% CI & P-value \\
\hline $\mathrm{HbA} 1 \mathrm{c}$ & $8.490 \pm 2.488$ & $8.548 \pm 2.322$ & $9.765 \pm 2.139$ & -0.07272 & $-0.2913-0.1530$ & 0.5162 \\
\hline
\end{tabular}

\section{Discussion}

Diabetes mellitus is the commonest metabolic disorder and has a high prevalence in India. The progress of the diabetic patients largely depends on the complications seen in the natural course of illness.

Our study showed that the 5-10 years of duration of diabetes was present in $42 \%$ cases and less than 5 years duration of diabetes was present in $40 \%$. Only $18 \%$ cases had more than 10 years of diabetes. Bharti Prakash et al (2018) 12 found that the patients of DM type 2 were divided into seven age groups according to their age in years 11 to 20 is the lowest and 71 to 80 years is the highest group. Tri J.E. Tarigan et al (2015)13 found maximum patients (46\%) were seen more than 70 years of age group. Most of the subjects who came to the clinic had experienced type 2 diabetes for more than five years and only $5 \%$ of them had been diagnosed type 2 diabetes since less than a year ago.

The overall male to female ratio was approx 1:1 in our study. Bharti Prakash et al (2018)12 included out of 464 diabetes type 2 patients comprising of 256 male and 208 female.

Poor glycaemic control indicated by raised glycosylated haemoglobin was significantly associated with increased incidences of diabetic nephropathy. Gupta et al (1991) from New Delhi found that glycosylated haemoglobin was significantly higher in microalbuminuric NIDDM patients. 14

Type 2 diabetes patients with chronic complications have higher risk to be hospitalized. This trend may be caused by a higher need of hospital care to manage the chronic complications, such as acute stroke, acute heart attack, severe kidney failure, and diabetic foot problems.

\section{Conclusion}

We concluded that on applying spearman correlation for microvascular complications, a positive association was observed for age of patients, duration of diabetes, HbA1C. Duration of diabetes was found to be a main culprit of micro vascular complication. No such studies in the past have been done in this region, through which comparisons could be made.

\section{References}

1. Kahr CR, Weire GC, Lea and Febiger. Joslin's diabetes mellitus, 13th ed. Philadelphia, 1994; 193-194.

2. Huizinga MM, Rothman RL. Addressing the diabetespandemic: A comprehensive approach. Indian J Med Res 2006;124:481-4.

3. Wild S, Roglic G, Green A, Sicree R, King H. Global prevalence of diabetes: Estimates for the year 2000 and projections for 2030. Diabetes Care 2004;27:1047-53

4. Mohan V, Sandeep S, Deepa R, Shah B, Varghese C. Epidemiology of type 2 diabetes: Indian scenario. Indian J Med Res 2007;125:217-30.

5. Vishwanath BS, Darshan MV, Shekar MA. Prevention of chronic complications of diabetes mellitus - Does patient education score over treatment? Curr Sci 2002; 83:1435-6.

6. Boyko EJ, de Cowten M, Zimmer PZ. Features of the metabolic syndrome predict higher risk of diabetes \& impaired glucose toleranceA prospective study in Mauritius. Diabetes Care 2000; 23: 1242-1248.

7. Ramachandran A, Snehalatha $C$, Latha $E$ et al. Rising prevalence of NIDDM in an urban population in India. Diabetologia 1997; 40: 232237.

8. Harati Y. Diabetic peripheral neuropathies. Ann Intern Med 1987; 107: 546-559.

9. Guy RJC, Clarke CA, Malcolm PN, Watkins PJ. Evaluation of thermal and vibration sensation in diabetic neuropathy. Diabetologia 1985; 28 : 131-137

10. Nicolosi A, Marighi PE, Rizzardi P, Osella A, Miglior S. Prevalence and causes of visual impairment in Italy. Int J Epidemiol 1994; 23:359- 
64

11. El-Shazly M, Zeid M, Osman A. Risk factors for eye complications in patients with diabetes mellitus development and progression. East Mediterr Health J 2000; 6:313-25.

12. Prakash B, Yadav LK. A study of micro vascular complications and associated risk factors in newly diagnosed patients of type 2 diabetes mellitus. Int J Community Med Public Health 2018;5:2338-43.

13. Tri J.E. Tarigan, Em Yunir, Imam Subekti, Laurentius A. Pramono,
Diah Martina. Profile and analysis of diabetes chronic complications in Outpatient Diabetes Clinic of Cipto Mangunkusumo Hospital, Jakarta. Med J Indones. 2015;24:156-62

14. Gupta DK, Verma LK, Khosla PK, Dash SC. The prevalence of microalbuminuria in diabetes: a study from North India. Diabetes Research and Clinical Practice 1991;12:125-128.

Copyright: (C) the author(s), 2019. It is an open-access article distributed under the terms of the Creative Commons Attribution License (CC BY 4.0), which permits authors to retain ownership of the copyright for their content, and allow anyone to download, reuse, reprint, modify, distribute and/or copy the content as long as the original authors and source are cited.

How to cite this article: Gupta AK. A Correlation of Duration of Diabetes with Glycemic Indices in the Type 2 Diabetes Mellitus: A Prospective Study. Asian J. Med. Res. 2019;8(3):ME04-ME06.

DOI: dx.doi.org/10.21276/ajmr.2019.8.3.ME2 